\title{
Digitally Controlled ZVS Quasi-Resonant Boost Converter with M-type Switch
}

\author{
Taufik, Senior Member, IEEE, Patrick Luther, and Makbul Anwari, Member, IEEE
}

\begin{abstract}
This paper presents the analysis, modeling and design of Zero-Voltage-Switching (ZVS) quasi resonant boost converter. The use of M-type switch in the topology will be described, including circuit's mode of operation along with the derivations of critical voltage and current equations in each mode. Computer simulation using OrCAD Pspice and hardware development for the resonant converter with digital control will be presented. Results from both simulation and laboratory measurements to compare with theoretical analysis will be discussed.
\end{abstract}

\section{INTRODUCTION}

Traditionally the switching for conversion of DC to DC has been done with what is known as pulse width modulation or PWM. This technique is efficient and has been used in the past to a great extent. However, the use of a PWM converter has its drawbacks. The converter's instantaneous switching allows the switch to turn on when the voltage is at a maximum and thus causing switching power losses. Unfortunately switching power loss worsens as converter's switching frequency increases. The use of an auxiliary circuit called the snubber has brought some results that have decreased switching losses, but not necessarily the overall losses of the converter. There is a better method called the soft-switching method.

Through the use of soft-switching, the switch will transition from its on-state to its off-state (and vice versa) while either the switch's voltage or current is at zero. This will prevent the occurrence of switching losses. Soft-switching topologies are broadly characterized into two types: zerovoltage and zero-current. Zero-current is when the switching transients are made at, or close to, a zero current level. Zerovoltage is when the switching transients are made at, or close to, a zero voltage level.

One way to implement soft-switching is by means of a resonant circuit. A resonant circuit commonly involves an LC tank that will reshape the switching waveform to a sinusoidal shape, thus naturally bringing the current or voltage of the switch to zero. This paper will focus on the zero-voltageswitching (ZVS) of a quasi-resonant (QR) boost converter. The name quasi-resonant must owe to the fact that these converters are not completely resonant. The resonance only takes place during the off-time of the switch, not continually during the switching process as in fully resonant systems.

Taufik is with the Electrical Engineering Department, Cal Poly State University, San Luis Obispo, California, USA (e-mail: taufik@)calpoly.edu).

Patrick Luther is with Applied Technologies Associates in Paso Robles, California, USA.

M. Anwari is with the Faculty of Electrical Engineering, Universiti Teknologi Malaysia (e-mail: makbul@)ieee.org).
The control of these quasi-resonant converters can be complex, to say the least. Traditionally the control has been analog based, but as we step into the future we see a digital world emerging. Among earlier introductions of zero voltage switching are those presented by Vinciarelli [1], Buchanan [2], and Miller [3]. Their initial ideas concerning the topic went on to encourage others. Most important of these are Lee [4], [5] [6], and his coauthor Liu [7], [8]. Working with these two and on his own, was Oruganti [9], [10] who presented state-plane analysis of resonant converters. Kazimierczuk wrote some important papers concerning zero voltage switching and resonant converters [11], [12], [13]. Despite this, the study of ZVS QR quasi-resonant converter seems to have limited coverage. In particular, the converter that proposes to use the ZVS in conjunction with the boost converter has rarely been covered in the literature. In addition, digital control implementation of ZVS QR boost has not been discussed anywhere. Therefore, the objective of this thesis is to first develop a mathematical analysis to understand the operation of the ZVS QR boost converter. Then, computer simulation will be performed to prove the mathematical analysis. Finally, hardware implementation using digital control will be designed and built to investigate the operation of the converter.

\section{ZVS QR BOOST CONVERTER}

\section{A. ZVS QR Boost Converter Basics}

The quasi-resonant boost converter is very much like a conventional PWM boost converter. The main difference is that a resonant LC circuit has been added as a resonant tank around the switch in order to create a soft switching situation.

\section{B. Quasi-Resonant Voltage Mode Switch Types}

There are two types of resonant switches for quasiresonant converters. There are labeled L-type and M-type. Out of these types of resonant switches, there are half-wave mode and full-wave mode varieties. Figures 1 to 3 show the representations of the M-type resonant switches. As illustrated in these figure, the M-type has a unique property that the resonant capacitor is always located across the switch.

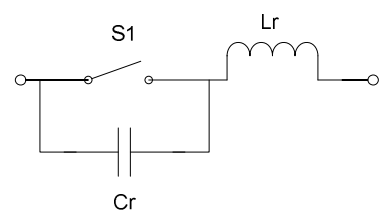

Fig. 1. M-type switch 


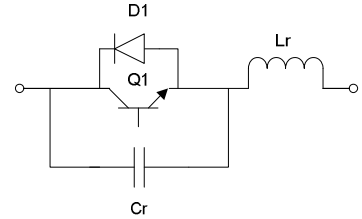

Fig. 2. M-type half-wave mode switch

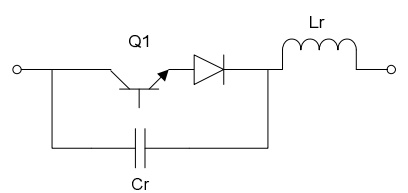

Fig. 3. M-type full-wave mode switch

\section{M-Type ZVS QR Boost Converter Modes of Operation}

The circuit presented in this paper can be seen in Figure 4. The circuit is a conventional boost converter with an M-type resonant switch replacing the single switch. .

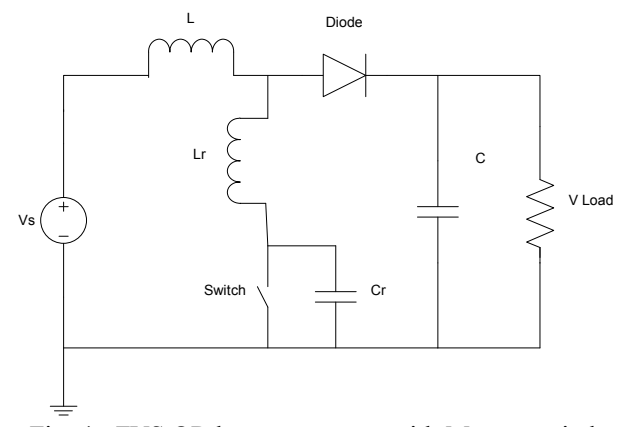

Fig. 4. ZVS QR boost converter with M-type switch

The circuit could be further simplified by modeling the input side as a constant current source, while the output as a constant voltage source. This is shown in Figure 5.

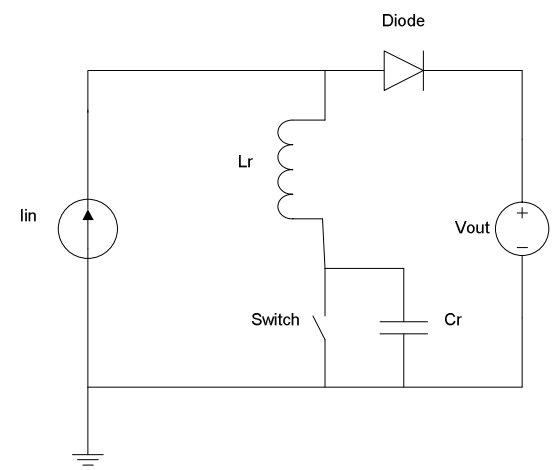

Fig. 5. Simplified ZVS QR boost converter with M-type switch

The waveform for circuit analysis is presented in Figure 6 to help visualize what is happening during the different modes of operation. Unlike the conventional PWM Boost Converter, which has two modes of operation, the quasi-resonant boost converter has four modes of operation. They are generally known as the capacitor charging mode, resonance mode, inductor charging mode, and freewheeling mode. Mathematical analysis of each mode is presented in the following section.

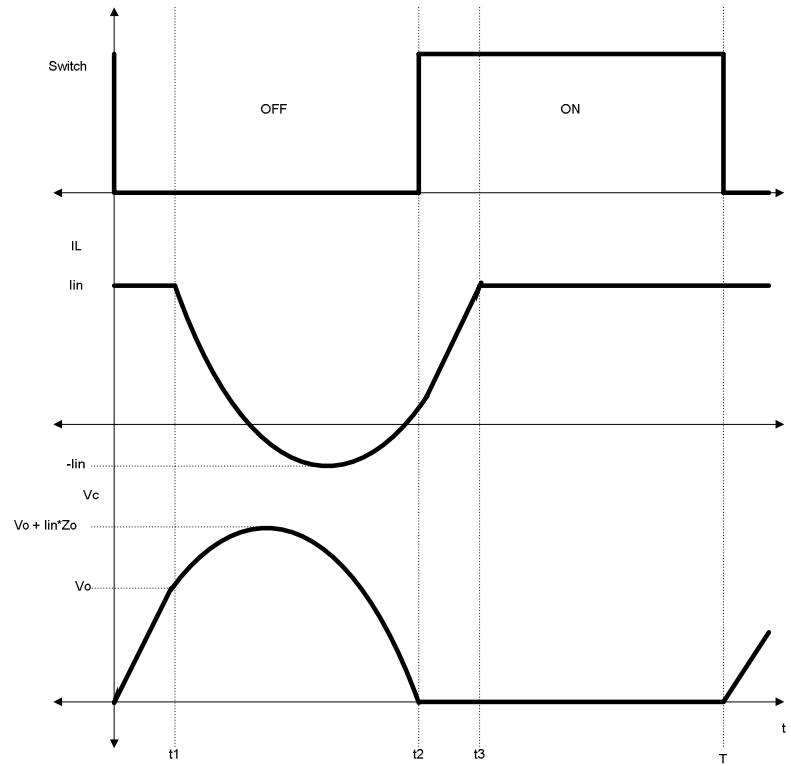

Fig. 6. ZVS QR boost converter waveform

III. Mathematical ANALYSIS

\section{A. Capacitor Charging Mode $\left(0 \leq t \leq t_{1}\right)$}

From 0 to $t_{l}$ in Figure 6, the switch is open and the diode is off and the circuit is now shown in Figure 7.

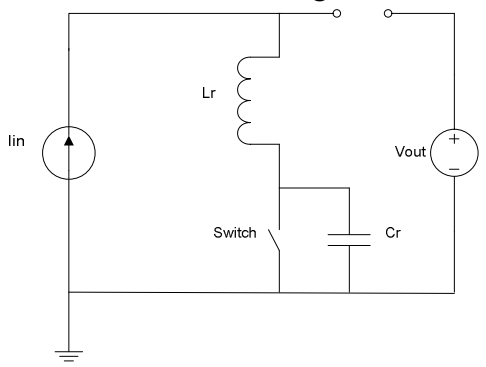

Fig. 7. Capacitor charging mode (switch off, diode off)

Just before this stage at $t<0$ the switch is closed and diode is off. At $t=0$ the switch is turned off and the diode stays off. The current through the inductor is equal to the input current, $I_{I N}$ and is the peak current at a constant value running through the inductor. Therefore, the inductor voltage is zero. The input current is also equal to the capacitor current:

$$
I_{I N}=i_{L}=i_{C}=C \frac{d v_{C}}{d t}
$$

Solving for the time at $t_{1}$ yields:

$$
v_{C}\left(t_{1}\right)=V_{O}=\frac{I_{I N}}{C} t_{1}
$$

The time $\mathrm{t}=\mathrm{t}_{1}$ can be computed by using equation (2):

$$
t_{1}=\frac{C \times V_{O}}{I_{I N}}
$$

The voltage across the diode is therefore:

$$
v_{d}(t)=V_{O}-v_{C}(t)=V_{O}-\frac{I_{I N}}{C} t_{1}
$$

Equation (4) shows that when the capacitor voltage reaches $V_{o}$ at $t_{1}$, diode voltage is zero and the diode is ready to turn on. 


\section{B. Resonance Mode $\left(t_{1} \leq t \leq t_{2}\right)$}

During this mode, $\mathrm{t}_{1} \leq \mathrm{t} \leq \mathrm{t}_{2}$ in Figure 7, the switch is still open and the diode becomes forward biased and begins conducting current. Figure 8 shows the circuit of this stage.

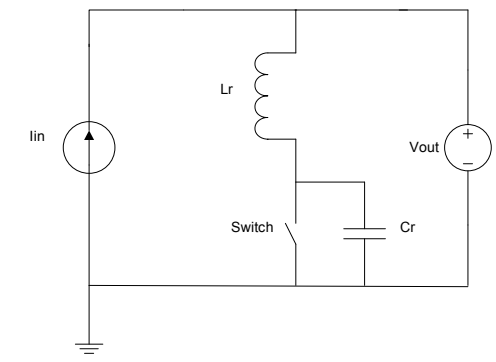

Fig. 8. Resonance mode (switch off, diode on)

When the time $t$ becomes equal to $t_{1}$ the switch remains open but the diode turns on. The capacitor voltage becomes equal to the output voltage. The inductor current also begins to descend at this point in time due to the fact that inductor, $L_{r}$ and capacitor, $C_{r}$ are resonating. This implies that initially, $v_{C}\left(t_{1}\right)=V_{O}$ and $i_{L}\left(t_{1}\right)=I_{I N}$. By using KVL:

$$
L \frac{d i_{L}}{d t}+v_{C}(t)=V_{O}
$$

Solving the differential equation using initial condition $\mathrm{I}_{\mathrm{IN}}$ :

$$
i_{L}(t)=I_{I N} \cos \omega_{O}\left(t-t_{1}\right)
$$

The capacitor voltage is expressed as:

$$
v_{C}(t)=\frac{1}{C} \int_{t 1}^{t} I_{I N} \cos \omega_{O}\left(\lambda-t_{1}\right) d \lambda+V_{O}
$$

which simplifies to:

$$
v_{C}(t)=V_{O}+I_{I N} Z_{O} \sin \omega_{O}\left(t-t_{1}\right)
$$

Equation (8) shows that the peak capacitor voltage is:

$$
v_{C}(t)=V_{O}+I_{I N} Z_{O}
$$

Solving for $t_{2}$ results in the following equation:

$$
t_{2}=t_{1}+\frac{1}{\omega_{O}} \sin ^{-1}\left[\left(\frac{V_{O}}{I_{I N} \times Z_{O}}\right)+\pi\right]
$$

\section{Inductor Charging Mode $\left(t_{2} \leq t \leq t_{3}\right)$}

During this mode, the inductor's magnetic field is charged as the current passes through its coils. Also, the switch is closed and the diode is forward biased or conducting. Figure 9 shows how the circuit appears during this stage. The inductor current is rising linearly according to the equation:

$$
v_{L}=L \frac{d i_{L}}{d t}=v_{O}
$$

The capacitor voltage has reached zero at the time the switch is closed. The switch and the diode are both conducting. Placing a diode in anti-parallel with the capacitor clamps the negative going voltage of the capacitor, referred to as halfwave mode. Initially at $t=t_{2}, v_{C}\left(t_{2}\right)=0$ and

$$
i_{L}\left(t_{2}\right)=I_{I N}\left[1+\cos \omega_{O}\left(t_{2}-t_{1}\right)\right]
$$

The inductor voltage is determined as follows:

$$
\begin{aligned}
& v_{L}+v_{C}=V_{O} \\
& L_{r} \frac{d i_{L}}{d t}=V_{O}
\end{aligned}
$$

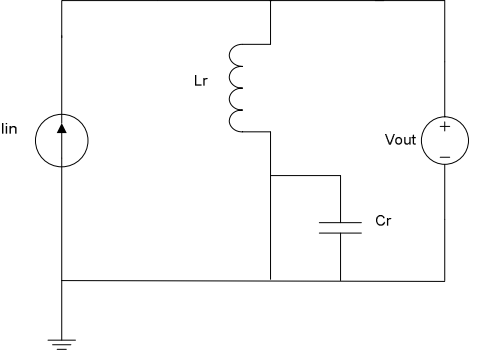

Fig. 9. Inductor charging mode (switch on, diode on)

Solving for the change of inductor current with respect to time:

$$
i_{L}(t)=\frac{V_{O}}{L_{r}}\left(t-t_{2}\right)+i_{L}\left(t_{2}\right)
$$

Since $i_{L}\left(t_{2}\right)$ is the initial condition, equation (15) becomes:

$$
i_{L}(t)=\frac{V_{O}}{L_{r}}\left(t-t_{2}\right)+I_{I N}\left[\cos \omega_{O}\left(t_{2}-t_{1}\right)\right]
$$

At $t=t_{3}$ which marks the end of the inductor charging mode, $i_{L}$ reaches $I_{O}$ and the time interval between $t_{2}$ and $t_{3}$ is:

$$
\left(t_{3}-t_{2}\right)=\frac{L_{r}}{V_{O}} i_{L}\left(t_{2}\right)=\frac{L_{r}}{V_{O}} I_{I N}\left(1-\cos \omega_{O}\left(t_{2}-t_{1}\right)\right)
$$

\section{Freewheeling Mode $\left(t_{3} \leq t \leq T\right)$}

In this mode, the circuit performs a freewheeling action. This mode is marked by the switch being closed and the diode not conducting. The circuit is shown in Figure 10.

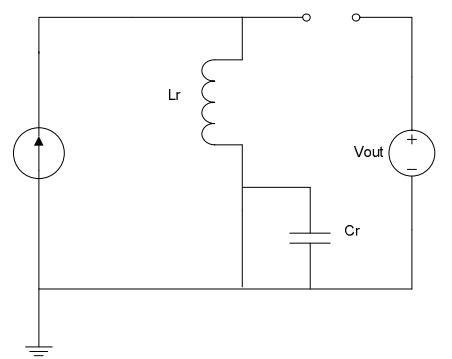

Fig. 10. Freewheeling mode (switch on, diode off)

At the end of the last stage when $t=t_{3}$, the diode turns off and the current source $I_{I N}$ runs straight into the inductor and transistor. The interval between $t_{3}$ and $T$ depends heavily on the switching frequency. At the end of this mode at time $t=T$, the cycle repeats as the switch is once again turned off.

\section{COMPUTER SimUlations}

\section{A. ZVS QR Boost Converter Design}

The design for the ZVS QR boost converter begins with determining certain parameters. The design procedure for this ZVS QR converter was derived from Kazimierczuk [13] and Batarseh [14]. The maximum output power for the converter was chosen to be $12 \mathrm{~W}$. The input voltage was selected to be $5 \mathrm{~V}$ while the output was $12 \mathrm{~V}$. The converter needs to run in continuous conduction mode with a peak to peak output voltage ripple of less than $0.5 \%$. The switching frequency was chosen to be $100 \mathrm{kHz}$. The minimum load resistance will be given as approximately, since the efficiency 
of the converter is less than $100 \%$. The maximum load resistance was selected to be approximately twice the minimum load resistance of $10 \Omega$. The following equation was derived in [13] for the normalized frequency:

$$
A=\frac{2 \pi}{M\left\{\pi+\frac{Q}{2 M}-\arccos \sqrt{1-\left(\frac{Q}{M}\right)^{2}}+\frac{M}{Q}\left[1-\sqrt{1-\left(\frac{Q}{M}\right)^{2}}\right]\right\}}
$$

The above equation was then plotted to develop a family of curves shown in Figure 11, which illustrates the voltage gain versus the normalized frequency. Figure 12 shows the normalized frequency as a function of the quality factor, $\mathrm{Q}$.

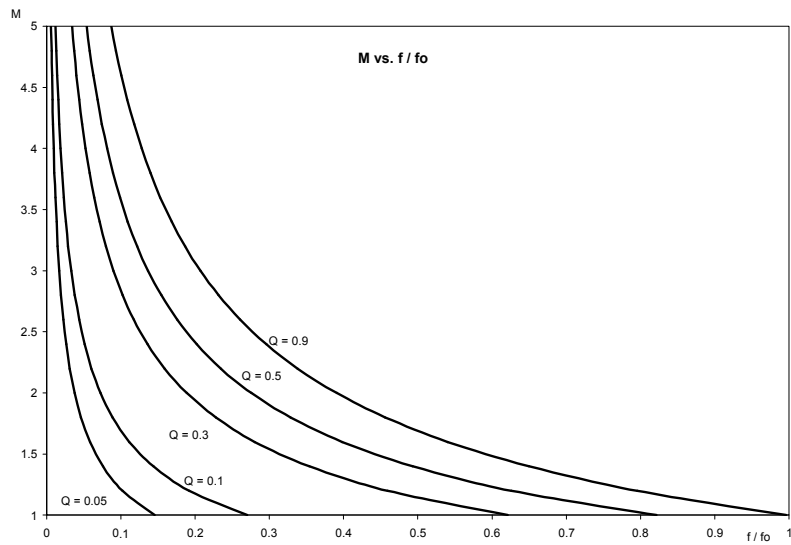

Fig. 11. Voltage gain versus normalized frequency

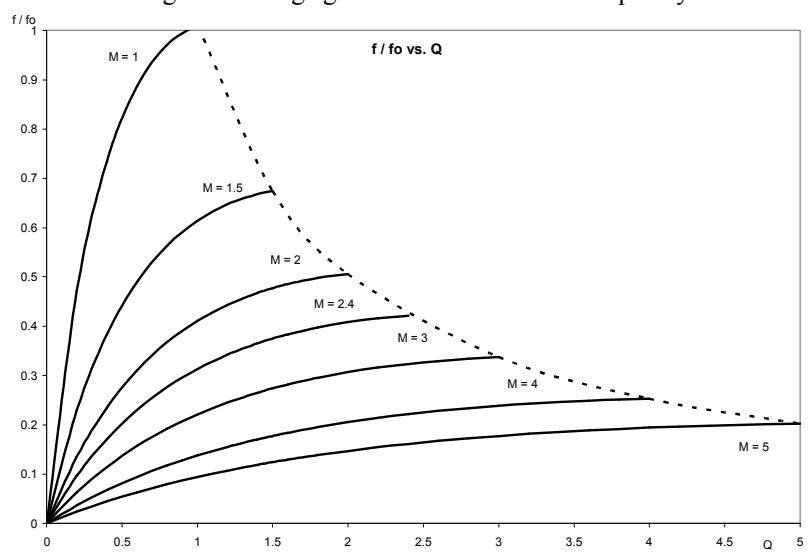

Fig. 12. Normalized frequency versus quality factor

From Figure 12, it can be determined that for an $\mathrm{M}\left(\mathrm{V}_{\mathrm{o}} / \mathrm{V}_{\text {in }}\right)$ 2.4 , the maximum quality factor would be $\mathrm{Q}_{\max }=2.4$ and the minimum quality factor would be $\mathrm{Q}_{\min }=1.4$. The approximate normalized frequencies can be determined as $A_{\max }=0.4$ and $A_{\text {min }}=0.3$, which yields the resonance frequency.

$$
f_{O}=\frac{f_{S}}{A_{\min }}=\frac{100 \times 10^{3}}{0.3}=333 \mathrm{kHz}
$$

The following equations are derived in order to help determine the values of the resonance inductance and capacitance.

$$
\begin{aligned}
& L_{r}=\frac{R_{L \min }}{\omega_{O} Q_{\min }}=\frac{10}{2 \pi \times 333 \times 10^{3} \times 1.4}=3.41 u \mathrm{H} \\
& C_{r}=\frac{Q_{\text {min }}}{\omega_{O} R_{L \text { min }}}=\frac{1.4}{2 \pi \times 333 \times 10^{3} \times 10}=66.9 n F
\end{aligned}
$$

The available values chosen are $\mathrm{L}_{\mathrm{r}}=3.9 \mathrm{uH}$ and $\mathrm{C}_{\mathrm{r}}=$ $0.1 \mathrm{uF}$. The maximum switching frequency is then:

$$
f_{\text {max }}=A_{\max } \times f_{O}=0.4 \times 333 \times 10^{3}=133 \mathrm{kHz}
$$

Results of computer simulations using OrCAD Pspice are shown in Figures 13 to 18 . Figure 13 shows the steady state output voltage of $12 \mathrm{~V}$ at $12 \mathrm{~W}$ with its peak to peak output voltage ripple of $41 \mathrm{mV}$ as shown in Figure 14.

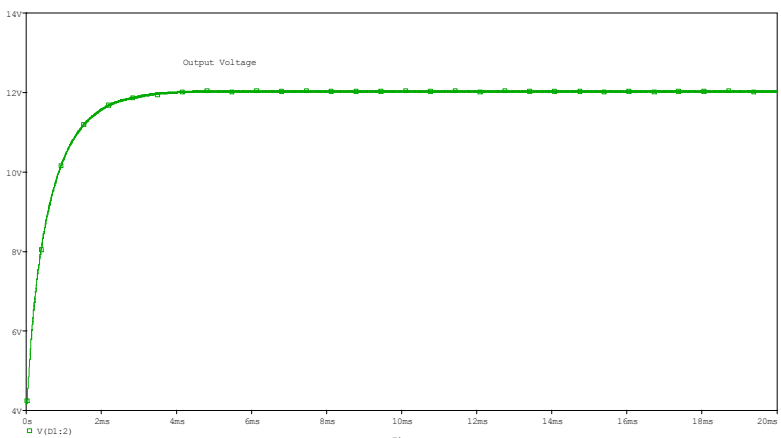

Fig. 13. ZVS QR boost converter Pspice output voltage

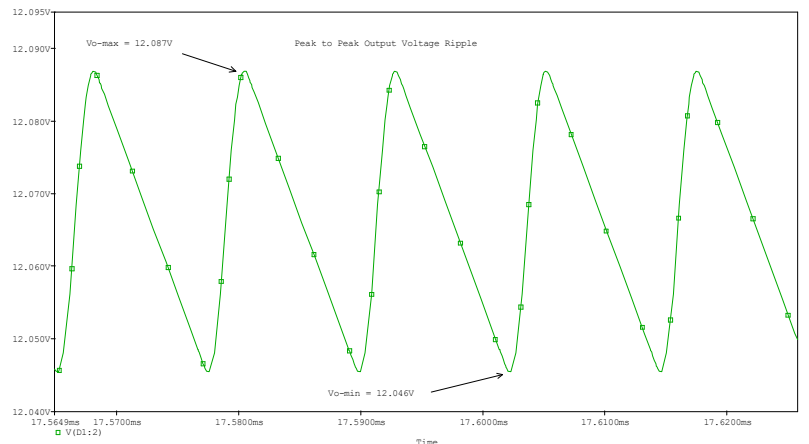

Fig. 14. ZVS QR boost converter Pspice peak to peak output voltage ripple

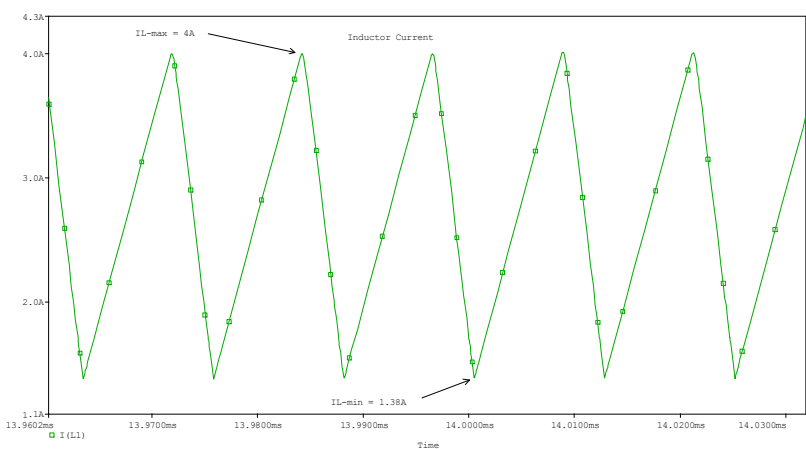

Fig. 15. ZVS QR boost converter Pspice inductor current

Figure 16 shows the inductor current maximum, minimum, and average values. The maximum value is found to be $4 \mathrm{~A}$, while the minimum value is $1.38 \mathrm{~A}$, and the average value is $2.69 \mathrm{~A}$. The maximum resonant capacitor voltage can be seen in Figure 16. Ideally, the value should be $40.8 \mathrm{~V}$ whereas the simulated result shows $38.7 \mathrm{~V}$. This lower value should make sense considering the non-ideal nature of the components.

The resonant inductor maximum and minimum currents, shown in Figure 17, should ideally be equal to the maximum input current, and the negative of that value respectively. The 
maximum current of the simulation seems to peak out at approximately $4 \mathrm{~A}$, but there is a transition of the maximum current that appears to have an average value of approximately $2.6 \mathrm{~A}$; which is close to the simulated input current value of 2.69A. The minimum value appears to peak of at $-3.82 \mathrm{~A}$ which is less than the value of $-2.69 \mathrm{~A}$.

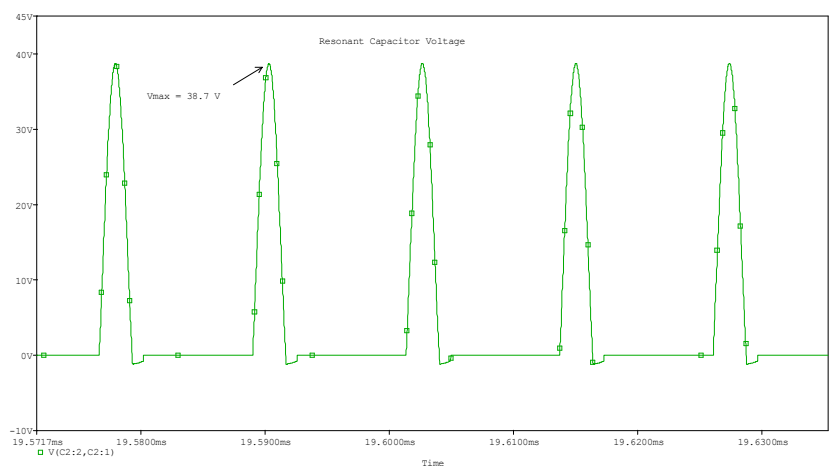

Fig. 16. ZVS QR boost converter Pspice resonant capacitor voltage

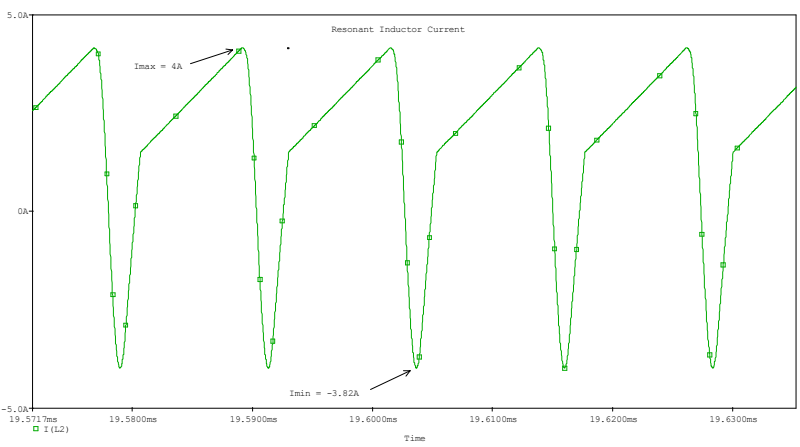

Fig. 17. ZVS QR boost converter Pspice resonant inductor current
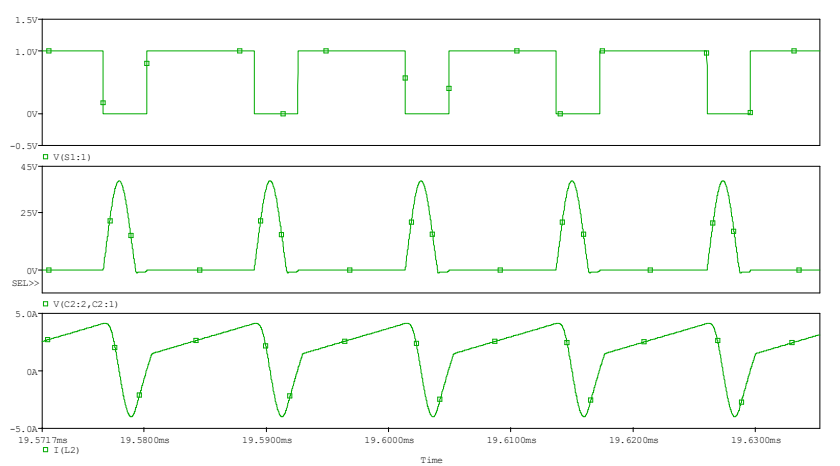

Fig. 18. ZVS QR boost converter Pspice total zero-voltage switch features

Figure 18 shows the overall progression of the resonant stage of the ZVS QR boost converter. It can be seen that upon turn-off the capacitor voltage begins to rise and the inductor current shortly after begins to fall. This is precisely what is expected to happen and is clearly shown.

\section{HARDWARE DESIGN}

Much of this digital control section comes from adaptations of the works in [15] - [18]. Typically, for a DC-DC converter control system, an analog system is implemented. For this paper, the use of a straightforward digital controller is brought forth; the analog error amplifier and pulse modulator have been replaced by a microcontroller. The controller that was chosen was Microchip PIC16F684 microcontroller. The overall digital control system can be seen in Figure 19.

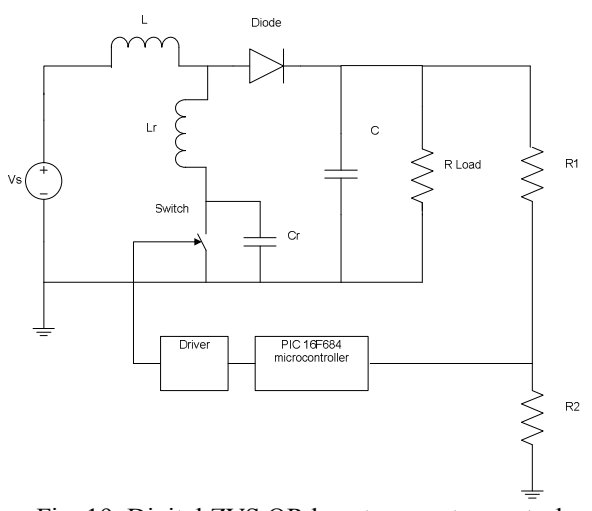

Fig. 19. Digital ZVS QR boost converter control

\section{A. Firmware Design}

The firmware that is implemented for the digital control is straight forward and could have been done in a number of different ways. The preferred method would be to use a comparator to monitor the feedback from the output, if this feedback is less than the set point then increase the frequency by skipping a pulse until the feedback reaches a control state. The rate of the frequency either raises the output voltage, with an increase; or lowers the output voltage with a decrease.

\section{B. Hardware Results}

Figure 20 shows the circuit board for the converter. Although the average output voltage of $12 \mathrm{~V}$ was achieved at light load, the converter could only produce $10.05 \mathrm{~V}$ with an output ripple voltage of $548 \mathrm{mV}$ at full load. This is mostly due to the stray components and real component's losses not accounted for during the design.

The input current through the main boost inductor is shown in Figure 21. The maximum value is approximately 4A which agrees with the simulation result, but the minimum value is $1.09 \mathrm{~A}$ which is lower than the simulated value of $1.38 \mathrm{~A}$. The resonant capacitor voltage was measured to be $27.5 \mathrm{~V}$, as shown in Figure 22, which is lower compared to the simulated value of $37.4 \mathrm{~V}$. Figure 23 shows the resonant inductor current whose maximum value is approximately $4 \mathrm{~A}$, but the transition has an average value of approximately $2.5 \mathrm{~V}$, which is desirable. Finally, Figure 24 demonstrates the soft-switching action. As the switch turns off, its voltage is at zero; but as the switch turns back on, it is happening at a small voltage.

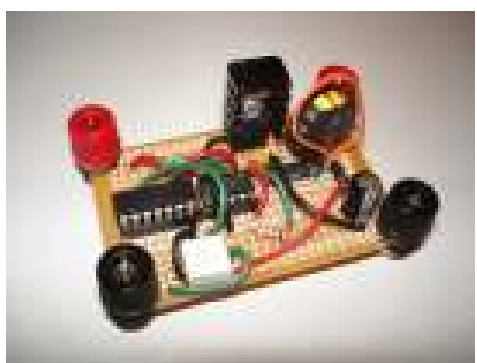

Fig. 20. Hardware circuit for the ZVS QR Boost Converter 


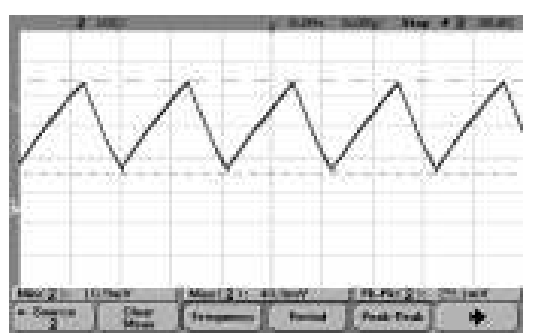

Fig. 21. Hardware Input current

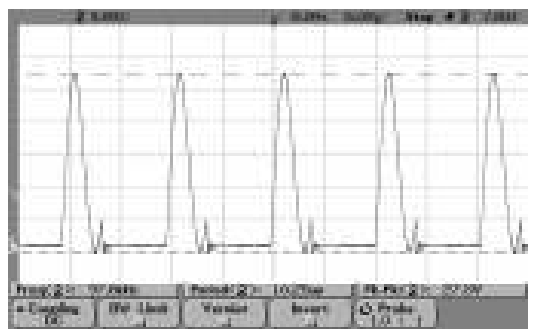

Fig. 22. Hardware resonant capacitor voltage

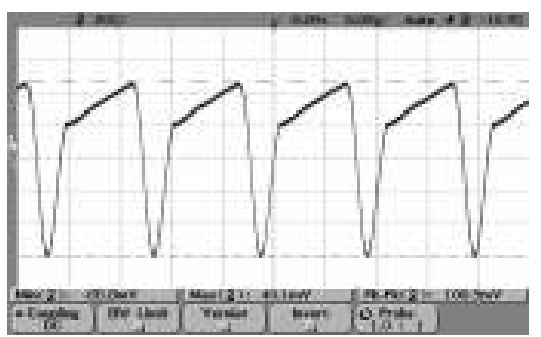

Fig. 23. Hardware resonant inductor current

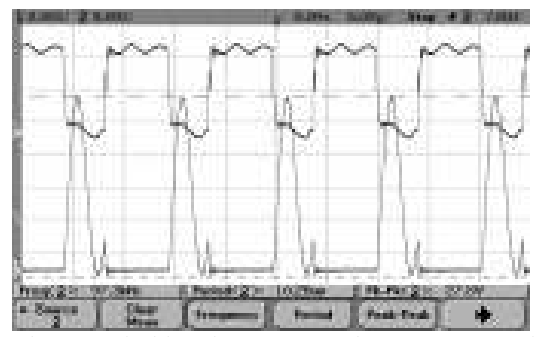

Fig. 24. Hardware switching frequency and resonant capacitor voltage

\section{CONCLUSION}

The main objective of this paper was to analyze, design, simulate, and build a ZVS QR boost converter along with a brief discussion of its digital control implementation. The resonant converter is used to allow for a soft switching situation allowing for higher switching frequency and less EMI noise from the converter. In turn, this will allow the use of smaller components, most importantly the inductor, which can be prohibitively large in some designs.

The digital control allows for more design control as well. Instead of having to rely on analog components, which can introduce noise, the signal may be placed into the digital domain and control can be achieved without introducing noise into the system. Overall, theoretical analysis, results from computer simulations and hardware agree with each other. There are some parameter values measured to be slightly higher or lower than the expected values; but this is common as stray losses and components are normally not counted for in the initial design.

\section{REFERENCES}

[1] Vinciarelli, P., "Forward Converter Switching at Zero Current," U.S. Patent 4,415,959, Nov. 1983

[2] Buchanan, E.E and Miller, E.J., "Resonant Switching Power Conversion Technique," IEEE Power Electronics Specialists Conference, PESC Record, 1975, pp. 188-193

[3] Miller, E.J., "Resonant Switching Power Conversions," IEEE Power Electronics Specialists Conference, PESC Record, 1976, pp. 206-211

[4] Lee, F.C., High Frequency Resonant, Quasi-Resonant and MultiResonant Converters, Virginia Power Electronics Center, 1991

[5] Lee, F.C., "High Frequency Quasi-Resonant Converter Technologies," Proc of the IEEE, Vol. 76, No. 4, April 1988, pp. 377-390

[6] Lee, F.C., "Zero-Voltage Switching Quasi-Resonant Converters," U.S. Patent 4,720,668, Jan. 1988

[7] Liu, K.H. and Lee, F.C., "Resonant Switches - A Unified Approach to Improve Performances of Switching Converters," Proc. Int. Telecomm. Energy Conf., 1984, pp. 344-351

[8] Liu, K.H. and Lee, F.C., "Zero-Voltage Switching Techniques in DC/DC Converter Circuits," Proc. IEEE Power Electron. Spec. Conf., 1986, pp. 58-70

[9] Liu, K.H., Oruganti, R., and Lee, F.C., "Resonant Switches Topologies and Characteristics," Proc. IEEE Int. Conf. Ind. Electron., 1998, pp. 509-521

[10] Oruganti, R., "State-Plane Analysis of Resonant Converters," Ph.D. Dissertation, Virginia Polytechnic Institute, 1987

[11] Kazimierczuk, M.K., "Analysis and Design of Buck/Boost ZeroVoltage-Switching Resonant DC/DC converter," IEEE Proceedings Vol. 136, No. 4, August 1989, pp. 157-166

[12] Kazimierczuk, M.K., "Design-Oriented Analysis of Boost Zero-Voltage Switching Resonant DC/DC Converter," IEEE Transactions on Power Electronics, Vol. 3, No. 2, April 1988, pp. 126-136

[13] Kazimierczuk, M.K. and Czarkowski, D., Resonant Power Converters, New York: Wiley Interscience 1993

[14] Batarseh, I., Power Electronic Circuits, New York: Wiley 2004

[15] Predko, M., Programming and Customizing PICmicro Microcontrollers, New York: McGraw-Hill 2002

[16] Charais, J., Software PID Control of an Inverted Pendulum Using the PIC16F684, Microchip Application Note AN964, 2004

[17] Condit, R., Low Cost USB Microcontroller Programmer: The Building of the PICkit 1 Flash Starter Kit, Microchip Application AN258, 2003

[18] Darmaawaskita, H., DC/DC Converter Controller Using PICmicro Microcontroller, Microchip Application Note AN2 16, 2000

\section{BIOGRAPHIES}

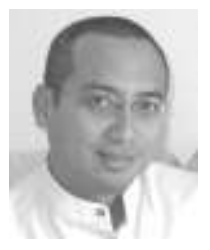

Taufik (M'1997, SM'2007) was born in Jakarta, Indonesia. He received his BS in Electrical Engineering from Northern Arizona University in 1993, MS in Electrical Engineering, and Doctor of Engineering from Cleveland State University in 1999. Since then, Dr. Taufik joined the Electrical Engineering Department at California Polytechnic State University in San Luis Obispo where he is currently an Associate Professor.

Patrick F. Luther graduated from California Polytechnic State University, San Luis Obispo with MS in Electrical Engineering in 2006. He is currently working for Applied Technologies Associates in Paso Robles, CA as an electronic engineer.

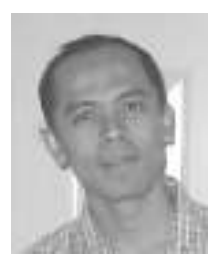

Makbul Anwari (S'2004-M'2006) was born in Pontianak, Indonesia. He received the B.Eng. degree in Electrical Engineering from University of Tanjungpura, Indonesia, in 1995, the M.Eng. degree in electrical engineering from Bandung Institute of Technology, Indonesia, in 2000, and the Dr.Eng. degree from Nagaoka University of Technology, Japan, in 2005. From 1995 to 2006, he joined the Electrical Engineering Department at University of Tanjungpura, Indonesia, where he was a Lecturer. Currently, he is a Lecturer at the Department of Energy Conversion, Universiti Teknologi Malaysia. Dr. Anwari is a member of the IEEE Power Engineering and Industry Application Societies. 